\title{
Teachers' Perspectives of School and Family Cooperation: A Case Study in China
}

\author{
Gurnam Kaur Sidhu ${ }^{1}$, Palani K. Veloo ${ }^{1}$, Yin Xiaoyang ${ }^{1}$, Parmjit Singh Aperapar Singh ${ }^{2, *}$ \\ ${ }^{1}$ Faculty of Education, SEGi University, Malaysia \\ ${ }^{2}$ Faculty of Education, UiTM Selangor, Campus Puncak Alam, Malaysia
}

Received June 28, 2019; Revised September 5, 2019; Accepted September 12, 2019

Copyright $\odot 2019$ by authors, all rights reserved. Authors agree that this article remains permanently open access under the terms of the Creative Commons Attribution License 4.0 International License

\begin{abstract}
Numerous studies all around the globe have revealed that school and family partnership are a significant factor in students' academic achievement. The main purpose of this case study was to examine teachers' perceptions of school and family cooperation in two primary schools located in China. The study involved two randomly selected primary schools located in an urban district of Yin Chuan, Ning Xia Hui-Autonomous Region in China. The sample comprised of 100 teachers and data were collected via a questionnaire and semi structured interviews. The findings of this study revealed that teachers generally held positive perceptions towards school and family cooperation and admitted it was a crucial relationship for students' success at school. Inferential statistics further showed that there was no significant difference in teachers' perceptions based on gender and teaching experience. Interviews, however, revealed that the main challenges faced by teachers were time constrains, work stress, a lack of cooperation from parents and communication issues between the two groups.
\end{abstract}

Keywords Teachers' Perspectives, School and Family Cooperation, Gender, Teaching Experience, Communication

\section{Introduction}

The school and family partnership is a collaborative relationship where school activities involve school staff, parents and other family members of students at a school. Such collaborative relationships can bring about a positive effect on students both in terms of educational achievement and social well-being. Studies have shown that when parents work collaboratively with teachers and both parties are engaged in the children's school activities and school work it can lead to a significant improvement in academic success [1].

Urie Bronfenbrenner's ecological model served as a framework for this study as it explored the relationship between home (i.e. parents) and school (teachers) and how it influences the education of the child. Based on Bronfenbrenner's ecological systems theory, parents form the microsystem which is the smallest and closest to a child and parents' are thus often viewed as the first teacher for their children. The influence at this stage is said to be the strongest to impact a child compared to the other stages of a child's development and any success or failure experienced by the child or the family (e.g. getting a promotion or losing a job) at this stage of life can impact the entire family structure [2]. Therefore, at this stage, parents need to develop a strong bond with their children and be active to reinforce learning in the home environment

The second layer, referred to as the mesosystem, works like a layer that provides a connection between the child's structures in the microsystem. For example, the relationship between the child's parents and the teacher, between the child and his neighbourhood and the religious place. At this stage the child can be seen as becoming a more active participant in the interactions with the new environment. This is time when school and family cooperation is of utmost important as the child tries to bridge what is learnt at home with what is happening in the school. In such a situation the critical call for both parents and teachers working collaboratively for the child's development cannot be underscored. Once children enter the mesosystem, they will spend most of their time at school and if a child has difficulty adjusting or is experiencing learning problems or behavior issues, teachers should work collaboratively with parents to know where the problem is coming from and how both parties can help solve the issue [2].

Teachers are hence viewed as the first school contact that children have in the new environment outside the 
security of their home. In such a situation, teachers' perceptions, beliefs, and prior experiences may influence their commitment and willingness to engage parents in student learning and success [3]. So teachers' perspectives and what they bring to the table in the school and family collaborative activities influence parent-teacher, parent-school, and parent-child relationships, which are a key to student development at school. Researchers claim that to make this relationship work, the most important factor is teachers' realization that school and family cooperation is important because the school is where the child's life and development is going to take place [4]. Henceforth, teachers need to be aware of how they can work alongside families to promote the social support that parents need for the holistic development of their children. This help can be characterised by various framework put forward by a number of researchers. The framework proposed by Epstein [5] suggested that as a beginning, teachers can help parents in the following six aspects:

- Learning At Home - Teachers can help provide parents with information and ideas as to how they can help their children learn at home. This may include both curriculum and co-curriculum activities such as helping them with homework strategies, how to supervise children and family reading and learning activities.

- $\quad$ Parenting- Helping here refers to assisting parents with parenting skills in upbringing a child and setting home conditions for effective student learning and development. It may include limiting television viewing and setting daily time tables.

- Communication - Communicating with parents about school programs and student progress through effective two-way communication. Emails and phone calls can help communicate to parents their child's progress and better understanding of school policies.

- Volunteering - Teachers can recruit and organize parents' help to support both school and student activities at school, home, and other locations such as school cleanliness and safety campaigns.

- Decision making - Parents can be called to be involved as members of committees such as the PTA (parent-teaching association) and other school related activities to make decisions on issues relating to school and student learning.

- Collaborating with the Community-Here teachers can work collaboratively with families to identify and integrate resources and other services from the community to further enhance and strengthen school activities and programs to enhance student learning experiences.

All the above mentioned strategies indicate how teachers can work collaboratively with families to enhance student learning experiences. Though numerous studies which have been conducted to explore this relationship, there is however scarce empirical evidence of studies involving primary school teachers' perspectives in China.

\section{The Study}

The main aim of this study was to investigate Chinese primary school teachers' perspectives on school and family cooperation. Besides that, the study also examined if there was a significant difference in teachers' perspectives based on gender and teaching experience.

This case study involved two randomly selected primary schools located in Ning Xia Hui-Autonomous Region in Northwest China. The sample involved 50 randomly selected teachers from each school and the final sample comprised 100 teachers and all were graduates with a university degree. The demographic profile revealed that $29 \%$ were males whilst the remaining $71 \%$ were females. In terms of teaching experience, 34 teachers had between one (1) to five (5) years of teaching experience, $28 \%$ of them possessed between six (6) to ten (10) years of experience whilst the remaining 38 teachers had more than 10 years of experience.

Data for the study was collected via a mixed-methods involving a questionnaire and semi-structured interviews. The Teacher Questionnaire covered six main constructs namely, cooperation with parents and their children, teacher-parent cooperation, role of school in school-family cooperation, teacher-parent communication, parent volunteerism and challenges faced by teachers. Respondents were required to respond to a five-point Likert scale where a score of one indicated strong disagreement whilst a score of 5 indicated strong agreement. The questionnaire was validated by a panel of three experts from a university and a pilot test was conducted to establish the reliability which stood at 0.937 . The quantitative analysis was analysed using both descriptive and inferential statistics using SPSS version 22. The semi structured interviews were conducted with ten teachers and they were referred to as Teachers $(\mathrm{T})$ ranging from Respondents TA, TB, to TJ. The qualitative analysis was analysed using both inductive and deductive analysis to answer the research questions posed in the study.

\section{Findings and Discussion}

The following section will provide the findings of the study followed by a brief discussion of the teachers' perspectives on school and family cooperation in primary schools in China.

The findings in Table 1 below shows that overall teachers have positive $(\mathrm{M}=4.40, \mathrm{SD}=.319)$ opinions of school and family cooperation. They also indicated rather favourable responses to all the constructs investigated. 
Table 1. Teachers' Overall Perceptions of School-Family Cooperation $(\mathrm{n}=100)$

\begin{tabular}{|c|l|c|c|}
\hline No & \multicolumn{1}{|c|}{ Perception of Teachers } & Mean & SD \\
\hline 1 & $\begin{array}{l}\text { Teachers' cooperation with parents } \\
\text { \& children }\end{array}$ & 4.36 & .392 \\
\hline 2 & $\begin{array}{l}\text { Teacher-Parent Cooperation } \\
\text { Cooperation }\end{array}$ & 4.45 & .310 \\
\hline 4 & $\begin{array}{l}\text { Role of School in School-Family } \\
\text { Parents communication with } \\
\text { school/ teacher }\end{array}$ & 4.37 & .411 \\
\hline 5 & Parents' Volunteerism & 4.39 & .369 \\
\hline & Teachers Overall Perception & 4.40 & .319 \\
\hline
\end{tabular}

Scale: $1=$ Strongly Disagree, $2=$ Disagree, $3=$ Almost Agree, $4=$ Agree, $5=$ Strongly Agree)

These findings show that teachers agreed that they do take an interest in cooperating with parents to work together to help improve children's academic achievements $(\mathrm{M}=4.36, \mathrm{SD}=3.92)$. This shows that there is substantial cooperation between parents and teachers with respect to the child's work at school. Teachers are also of the view that there is substantial cooperation between the teachers and parents on parent-teacher cooperation $(\mathrm{M}=4.44, \mathrm{SD}=$ $3.10)$ as there is fairly good communication with parents and school authorities $(\mathrm{M}=4.40, \mathrm{SD}=4.80)$. On volunteering subscale, teachers felt that volunteerism among parents was fairly good $(\mathrm{M}=4.39, \mathrm{SD}=4.48)$.

\subsection{Teachers' Cooperation with Parents and Their Children}

Based on the ten items posed in this section, teachers indicated that they took an interest in working with parents to help improve students' academic achievements ( $\mathrm{M}=$ 4.36, $\mathrm{SD}=3.92)$. They also indicated substantial cooperation between them and parents to raise awareness on the importance of their children's education $(\mathrm{M}=4.69$, $\mathrm{SD}=.486)$. Teachers also highlighted they often send home school progress reports on children's academic achievement and offered suggestions to both students and parents as to how they could help improve children's performance $(\mathrm{M}=4.34, \mathrm{SD}=.713)$. These findings were also corroborated in the open-ended section of the questionnaire where teachers (20\%) highlighted that they encouraged families to be involved in a variety of ways (e.g. assisting in the classroom, giving talks, and leading activities) and how they could provide a good learning environment for children to study at home. Another $10 \%$ of them claimed that they assisted parents in helping their children solve academic learning problems whilst $15 \%$ of the teachers highlighted that they guided parents on relevant skills that they could employ to monitor and discuss homework with their children.

This was further elaborated by Respondent TF in the interview when she said that "today we have seen more cooperation between parents and teachers as there is more talk about how they can help and counsel their children on their learning, especially at home and school... my school also carries out training activities for parents and teachers too also talk with parents by telephone or WeChat to answer parents' questions."

\subsection{Parent- Teacher Cooperation}

Teachers were also in agreement that parent-teacher cooperation in their schools was good $(\mathrm{M}=4.45, S D=.310)$ and they agreed that school Parent Day helps parents and teachers to collaborate and learn more about the families $(M=4.52, S D=.685)$. Teachers felt that the parents' and teachers' face-to-face conversation about children's learning will improve parent's attitudes towards teachers $(M=4.34, S D=.713)$. Besides that, parents contacting with teachers helps to raise awareness on the importance of their children's education $(M=4.29, S D=.807)$.

The interviews highlighted that when teachers are aware of the need to cooperate with parents it will enhance their relationship and at the end of the day the child will benefit. More importantly, when teachers share information with parents, it helps build a strong and trustworthy relationship between the family and the educators. Respondent TC agreed that: "Building positive and healthy relationship with parents is important as it develops a good relationship between school and family and the establishment of this cooperation is in my opinion the first stage of great importance in contributing to the future success of students."

\subsection{Role of School in School-Family Cooperation}

Teachers' positive perceptions were also seen when exploring the role of school in the school-family cooperation. Teachers highlighted that their schools conducted numerous activities to enhance school-family engagement. The highest mean score was recorded for teachers' opinion that their schools respected the different cultures in their parent-student population $(M=4.60, S D$ $=.512$ ) and that their schools provided families with information and training on developing home conditions or environments that support learning $(M=4.59, S D=.552)$. They also agreed that their schools sponsored home visiting programs or neighborhood meetings to help families understand schools and to help schools to understand families $(M=4.52, S D=.594)$.

Similar sentiments were shared by teachers during interview sessions. Respondent TD further elaborated that "nowadays schools also organize Open Day where parents are invited to lectures.. this way parents further understand the way teachers teach so that parents can better guide their children to learn. In addition, our school also invited parents to come to school to supervise students' examination...I thinks children will be embarrassed and we believe they will not cheat when their parents supervise examinations." 
The findings of this study concur with findings obtained by Bakker, Denessen and Brus-Laeven who state that teachers should view the teacher-parent relationship positively [6]. They stress that teachers should establish trust, share learning goals to meet children's best interests, have open communication, and work together with parents to solve students' learning problems. This was also articulated by Kumari, who stressed that active collaboration should be shared responsibility among both parties [7]. Other researchers stress that teachers need to take the initiative to develop strategies for working with parents to enhance student learning experiences and academic achievement [8].

\subsection{Parents' Communication with School}

Teachers' perspectives revealed that communication between the two parties was good $(M=4.40, S D=.369)$ and they do contact parents if and when children have learning or behaviour problems $(M=4.64, S D=.502)$. Besides that, teachers highlighted that the school heads also had policies that encourage both teachers and parents to communicate frequently with each other on curriculum plans, expectations for homework, and how parents can help $(M=4.45, S D=.575)$. To establish quality communication between the school and family, teachers agreed that they kept records with sufficient information about their students' families. They also reiterated that school-family cooperation is good as teachers do publish regular school newsletters with up-to-date information for parents about special events, meetings, and parenting tips $(M=4.25, S D=.715)$. Teachers also pointed out that they conduct an annual survey for families to share information and concerns about student needs and reactions to school programs, and their satisfaction with their involvement in school. $(M=4.24, S D=.712)$.

The interviews further revealed that all ten teachers conducted an orientation program for parents so that they can establish quality communication between the school and family. Respondent TA pointed out that during the orientation program, parents are also made aware of annual school events and activities that how parents can work collaboratively with the teachers. Respondent TD further restated that continuous follow-up communication with parents was very important. She emphasized that: "each teacher in this school usually has her own system of communication between teacher and parents...many use WeChat . . but I think most of us still prefer to send printed notes and messages because some parents do not have Wechat. So I often send messages to parents to inform them of school or class activities. I also send notes to parents when there is a class test or class function or activities where parents can come and contribute...In my opinion, open communication especially two-way communication is healthy and beneficial to the teachers, parents and students."
The importance of two-way communication was also articulated by Epstein who claimed that communication between parents and teachers is vital in any parent involvement model as it helps parents to better understand their children's progress and school programs to improve their children's academic performance [5]. Researchers such as Hall and Quinn stress that the establishment of effective communication is regarded as an important requirement for the realization of effective and productive relationships and teaching processes [9]. Moreover a study conducted by Pride Survey highlighted that effective communication helps to establish good parent-teacher relationship as it lays the foundation for healthy parent-teacher cooperation and communication for years to come [10].

\subsection{Volunteerism among Parents}

Teachers were also positives $(M=4.39, S D=0.373)$ of the activities conducted with volunteer parents. They stressed that they do encourage families to be involved with the school in a variety of ways $(M=4.57, S D=0.536)$. Besides that, teachers also helped parents to schedule regular interactive homework that requires students to demonstrate and discuss what they are learning with family members $(M=4.52, S D=0.502)$. Additionally, teachers also encouraged parent volunteers to contribute during school events at different times during the day and evening so that all families can attend some throughout the year $(M$ $=4.36, S D=.659$ ). Teachers also pointed out that they do try to reduce barriers to parent participation by providing transportation, childcare, and flexible schedules and create flexible volunteering and school events schedules, enabling parents who work to participate $(M=4.26, S D=$ 0.676).

Epstein notes that by volunteering in school activities parents can gain a measure of ownership in the school, and the school should work to recruit and organize parent help and support [5]. Sample volunteering practices show that schools can implement measures including organizing volunteer programs, creating a parent room or family resource center that provides resources for families, communicating methods which help inform parents of when volunteer projects are available, and developing parent patrols to help keep school safe.

\subsection{Challenges Faced by Teachers}

Teachers felt that the main challenge impeding school and family cooperation was time constraints due to heavy workload and work stress (33\%). They feel they did not have sufficient time to give their best in helping parents in school activities and some claimed they had no time for home visits especially to homes that really needed their help. Another $37 \%$ of them claimed parents did not have a good understanding and sense of the importance of family 
engagement in school events. They suggested that school authorities hold workshops to impress upon parents the importance of volunteering and involving themselves in school and family collaborative events. Approximately $11 \%$ of them opined that there was a lack of support from both parents and school authorities in school-family activities. Other reasons included a lack of effective communication between the two parties and parents' not giving sufficient attention to children's education.

Busy schedules of both parents and teachers was also articulated by other researchers who pointed that teachers' demanding jobs often required them to carry out many other duties besides teaching leaving them with little or no time to be engaged in meetings and discussions with parents [11].

\subsection{Teachers' Perspectives Based on Gender}

The study further explored if there was a significant difference between teachers' perspectives of school and family cooperation based on gender. To address the disparity in gender numbers $(\mathrm{M}=29, \mathrm{~F}=71)$, a post ad hoc Tukey test procedure was conducted to control the experiment wise error rate. The findings presented in Table 2 show that female teachers $(M=4.42)$ possessed slightly better perspectives compared to their male counterparts ( $M$ $=4.31$ ). Nevertheless, inferential analysis using a t-test revealed that the differences between male and female teachers were not statistically significant $[t=(-1.671), \mathrm{p}=$ 0.98 ] as the p-value was more than 0.001 . This means there was no difference between perceptions held by male and female teachers regarding school and family cooperation.

Table 2. TEACHERS' PERCEPTIONS BASED ON GENDER $(\mathrm{N}=100)$

\begin{tabular}{|c|c|c|c|c|c|c|}
\hline & Gender & $\mathrm{N}$ & Mean & SD & $t$ - values & $p$ - values \\
\hline \multirow{2}{*}{ Overall } & Male & 29 & 4.313 & .410 & \multirow{2}{*}{-1.671} & .098 \\
\cline { 2 - 6 } & Female & 71 & 4.429 & .269 & & \\
\hline
\end{tabular}

\subsection{Teachers' Perspectives Based on Teaching Experience}

The study also examined if there was a significant difference between teachers' perspectives of school and family cooperation based on teaching experience. The teaching experience was divided into three categories, namely below five (5) years, from six (6) to ten (10) years and more than ten (10) years. From the results illustrated in Table 3, it can be seen that teachers with more than ten years of teaching experience $(\mathrm{M}=4.45, \mathrm{SD}=.033)$ held slightly better perspectives compared to the other two groups. The results of the one-way analysis of variance to compare the perceptions of the three groups showed that there was no significant difference $(F=0.082, \mathrm{p}=0.921)$ among the teachers with varying level of years of teaching experience and their perception of school-family cooperation.
Table 3. TEACHERS' PERSPECTIVES BASED ON TEACHING EXPERIENCE $(\mathrm{N}=100)$

\begin{tabular}{|c|c|c|c|c|c|}
\hline Years of Experience & $\mathrm{N}$ & Mean & $S D$ & F-value & $P$-Value \\
\hline Below 5 years & 34 & 4.43 & .439 & & \\
\cline { 1 - 4 } 6 to 10 years & 28 & 4.44 & .417 & \multirow{2}{*}{0.082} & 0.921 \\
\hline More than 10 years & 38 & 4.45 & .033 & & \\
\hline
\end{tabular}

Cox highlighted that as an experienced teacher she had built a network of parents to work collaboratively with the school through activities such as having Parent-Teacher Conferences, Hosting Open House, keeping parents informed and recruiting volunteers [12].

\section{Conclusions}

The school and family partnership is often viewed as an important relationship for the success of student learning experiences at school. This study explored 100 teachers' perspectives of school and family cooperation from two primary schools in China. The results indicated that teachers held rather positive perceptions on all constructs examined, i.e. cooperation with parents and their children, teacher-parent cooperation, role of school in school-family relationships, teacher-parent communication and volunteerism among parents.

These positive perceptions displayed in the findings of this study could probably be due to the one-child policy in China. A majority of the parents (more than 95\%) in these two schools were products of the one-child policy implemented in 1979 by the Communist Party as a measure to curb the rising Han population. In fact, close to $75 \%$ of the parents in these two schools have only one child and this may be a contributory factor as to why teachers and parents are able to work collaboratively for the wellbeing of the pupils. The one one-child policy has witnessed positive cooperation between teachers and parents leading to student success at school. All these, bear testimony that teachers and parents must form effective partnerships so that positive student achievement can be fully realized.

Finally, it cannot be denied that the findings of the study cannot be generalised on the total population of teachers in these two schools or other primary schools in China because of the small sample size involving only 100 teachers. Moreover, though respondents were reminded to give their honest opinions to items in the survey questionnaire, the results can be subjective as some may have given socially accepted responses. Nonetheless, there is no denying that this study has managed to shed some light as to teachers' perspectives on school and family cooperation and the challenges that impede effective school and family cooperation. It is hoped that this study will spur more investigation into school and family cooperation in more primary schools across other regions in China involving much larger samples for more conclusive findings. 


\section{REFERENCES}

[1] D.C. Lueder. "Creating partnerships with parents:An educator's guide. Lancaster,PA:Tecnomic Publishing Company.1998.

[2] U. Bronfenbrenner. Ecology of the family as a context for human development: Research perspectives. Developmental Psychology,1986, 22(6), pp. 723-742.

[3] M.M. Patte, "Examining Preservice Teacher Knowledge and Competencies in Establishing Family-School Partnerships”. School Community Journal, 2011, 21(2), pp. 143-159.

[4] S. Petrovska \& S. Despina, "Cooperation (partnership) between school and family and student success. In 12th International Balkan education and science congress Education for life, work and well-being, Nesebar, Bulgaria.2017.

[5] J.L. Epstein, "School, family, and community partnerships: Preparing educators and improving schools", (2nd ed.). Philadelphia, PA: West view Press, 2011.

[6] J. Bakker, E. Denessen, E. Brus-Laeven, Socio-economic background, parental involvement and teacher perceptions of these in relation to pupil achievement. Educational Studies, 2007, 33(2), 177-192.

[7] G. Kumari. Teacher-parent Collaboration in two primary schools' Special Education Integrated Programme. Unpublished Thesis, University Malaya. (2016), p.iv.

[8] G. Hornby, C. Witte, A survey of parental involvement in middle schools in New Zealand. Pastoral Care in Education,2010, 28(1), pp.59-69.

[9] N. Hall, R. Quinn, Parental Involvement at the High School Level: Parents' Perspectives. Journal of Ethnic and Cultural Studies, 2014, 1(1), 13-21.

[10] Pride Survey. Tips for Strong Parent-Teacher Cooperation and Communication. Retrived on July 182019 from website:https://www.pridesurveys.com/index.php/blog/par ent-teacher-cooperation-communication/.

[11] T. M. Willemse, I. Thompson, R. Vanderlinde, T. Mutton. Family-school partnerships: a challenge for teacher education, Journal of Education for Teaching, 2018, 44:3, pp. 252-257.

[12] J. Cox. Parent-Teacher Collaboration Strategies That Work. TeachHub.com. Retrieved on July 152019 from http://www.teachhub.com/parent-teacher-collaboration-stra tegies-work. 